\title{
Study on the improvement of indoor hot and humid environment in Tibetan-style residential areas in northwest Sichuan
}

\author{
Sun Yidan ${ }^{1 *}$ \\ ${ }^{1}$ Architecture, Sichuan Agricultural University, Chengdu, Sichuan Province, 611830, China
}

\begin{abstract}
Indoor and outdoor thermal environment is under a definite impact on the human body, and to a large extent affects the comfort of people living. In this paper, the indoor and outdoor thermal and humidity parameters of Dongma village in the west of Sichuan Province were measured. On the living room and bedroom hot and humid comfort survey, the outside wall temperature and the local climate to do analysis, get January Dongma village typical residential indoor humidity environment, including the temperature of the living room is $6.6 \sim 19.5^{\circ} \mathrm{C}$, the relative humidity is $28.9 \sim 45.3 \% \mathrm{rH}$, the bedroom temperature is $3.5 \sim 19.8^{\circ} \mathrm{C}$, the relative humidity is $35.7 \sim 52.8 \% \mathrm{rH}$, the outdoor temperature is $2.4 \sim 27.4^{\circ} \mathrm{C}$, the temperature in the east is $-11.1 \sim-3.3^{\circ} \mathrm{C},-3.9 \sim 11.2^{\circ} \mathrm{C}$ at the west, $-8 \sim 2.8^{\circ} \mathrm{C}$ at the south, $-10.4 \sim-2.5{ }^{\circ} \mathrm{C}$ at the north, $1.6 \sim 29.2^{\circ} \mathrm{C}$ at the roof, and the solar radiation intensity is $422 \sim 739 \mathrm{~W} / \mathrm{m}^{\wedge} 2$. Combined with the above data, it is found that the overall insulation performance of the wall is good, but by the influence of the cold weather outside, the indoor temperature is still low, it is difficult to respond to the comfort needs of residents. The wall temperature is altered due to solar radiation. In view of the current situation of the indoor thermal environment in Dongma village, a series of optimization suggestions are submitted at the end of the paper.
\end{abstract}

\section{Case Description}

\subsection{Description of experimental subjects}

1.1.1. Experimental subjects. The experimental site is Dongma village in Zier Township, Xiaojin County, located in the northwest of Sichuan Province, in the southern part of Aba Tibetan Dai Autonomous Prefecture. There are Wenchuan County, Ganzi County, Baoxing County, Malcom county around it. Situated on the eastern edge of the Qinghai-Tibet Plateau, it is 3,425 meters above sea level, with a long, narrow mountainous terrain, the northeast is high, the southwest is low, and the terrain is high.

1.1.2. Construction form. Type of Tibetan residential in this area is a typical stone-wood structure of the hut, with earth and masonry as the wall, the internal beams as solid wood material. The wall is thick at the bottom and thin at the top, big at the bottom and small at the top. The building plan is plain and square. The experimental house is a two-story flat-top Tibetan-style residential house, divided into two floors, the bottom layer is an animal shed and a storage room, the storey height is low, the second floor is a residential layer, the functional layout includes living room, boiler, warehouse, bedroom, kitchen, toilet and bathroom.

\subsection{Monitoring point layout}

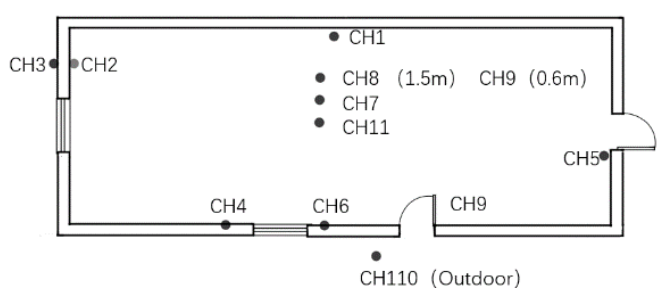

Figure 1. Monitoring point layout.

\section{Data Analysis}

\subsection{Analysis of outdoor temperature and humidity monitoring results}

As showed in the figure, the Testo175 data recorder and the JTNT-A/C multi-channel temperature heat flow tester were employed as an outdoor height of $1.5 \mathrm{~m}$ from the ground in Dongma village. The datum is given in Table 2, followed by the following data analysis diagram. According to Figure 2 of the data analysis, the average humidity for the day is $40.549 \% \mathrm{rH}$, the maximum is $56.9 \% \mathrm{rH}$, the occurrence time is about 10:00 on the $19 \mathrm{th}$, the minimum is $9.1 \% \mathrm{rH}$, the occurrence time is about $15: 00$ on the 19th. Its humidity change trend in the 18th 20:00 to 19th 10:00 overall show an upward tendency, 
and reached the highest value of humidity, there are small fluctuations between. The average temperature of the day is $6.253^{\circ} \mathrm{C}$, the maximum value is $28.2^{\circ} \mathrm{C}$, the appearance time is between $12: 00$ and 15:00, the minimum value $-2.6^{\circ} \mathrm{C}$, the appearance time is about 10:00. Its temperature change trend from 20:00 to 19th 10:00 overall show a downward trend, its decline process has a minor fluctuation, from 10:00 to 12:00 shows a rapidly upward trendency, the maximum difference is $20^{\circ} \mathrm{C}$. At about 12:00, outdoor temperature rapidly increased, combined with the day's weather conditions can be seen, the day around 12:00 began to clear, the sun became stronger, the sun radiation rose rapidly, so it would lead to a large change in humidity and temperature. The temperature peaked twice between 12:00 and 15:00 on that day, and when the weather was nice on the day, due to the impact of sunshine, during 12:00 and 15: 00, the maximum temperature and humidity minimum values appeared.

Table 1. Outdoor temperature and humidity.

\begin{tabular}{|c|c|c|c|c|c|}
\hline Device name: & \multicolumn{5}{|c|}{ Friday 1/19/2018 22:15:10 } \\
\hline Start date: 20:00:00 Thursday 2018/18 & & Min & Maximum & Mean & Limits \\
\hline End: 1/19/2018 Friday 22:10:00 & no name $\left[{ }^{\circ} \mathrm{C}\right]$ & -2.6 & 28.2 & 6.253 & $-20.0 / 70.0$ \\
\hline Measurement channel: 2 & no name $[\% \mathrm{rH}]$ & 9.1 & 56.9 & 40.549 & $0.0 / 100.0$ \\
\hline Measurements: 158 & & & & & \\
\hline
\end{tabular}

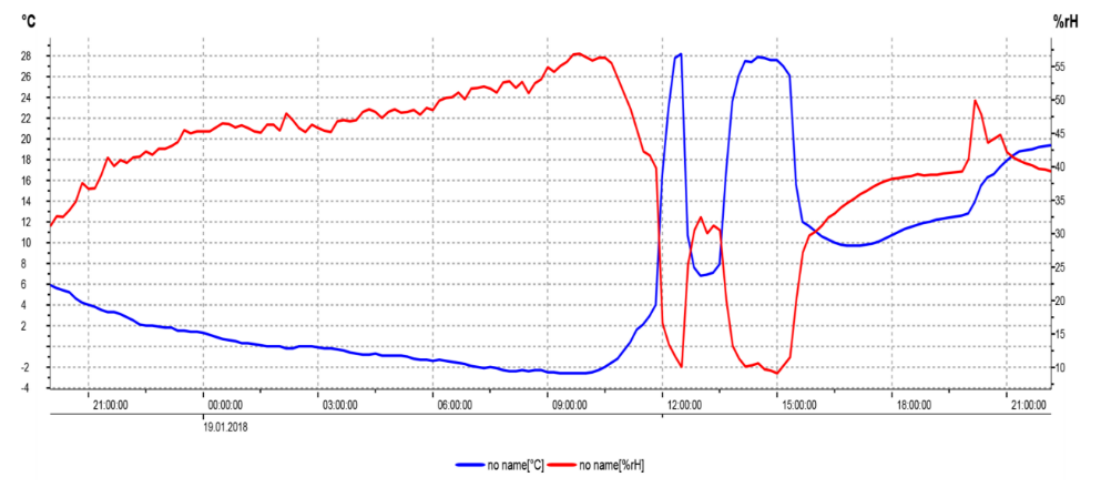

Figure 2. Outdoor temperature and humidity line chart.

\subsection{Analysis of indoor temperature and humidity monitoring results}

As showed in the figure, used the Testo175 data recorder and the JTNT-A/C multi-channel temperature heat flow tester to monitor, resulting in data as shown in Table 3 and Table 4, followed by the following data analysis diagram. According to Figure 3 of the data analysis, the average humidity for the day is $35.812 \% \mathrm{rH}$, with a maximum of $45.3 \% \mathrm{rH}$, with an occurrence time of approximately $21: 00$ on the 18th and a minimum of $28.9 \% \mathrm{rH}$, with an appearance time of approximately $21: 00$ on the 19th. Its humidity change trend from 18th 20:00 to 19th 0:00 shows edge trendy more unstable up and down, and the volatility is higher, and on the 19th 0:00 to 9:00 shows the overall upward trend, the volatility is small. Humidity fluctuates from 9:00 to 22:00. The average temperature of the day is $10.938^{\circ} \mathrm{C}$, the maximum value is $19.5^{\circ} \mathrm{C}$, the occurrence time is about $22: 00$ on the 19 th, the minimum is $6.6^{\circ} \mathrm{C}$, the appearance time is about 18th 21:00. Its temperature changes trend in the 18th around 20:00 to 22:00 shows up and down trend, the fluctuation range is about $1.5^{\circ} \mathrm{C}$. The time when the indoor temperature reached the highest and the outdoor temperature reached the highest time there was a delay, because the wall was hot and inert, the thermal stability was well. From 12:00 to 15:00 when the outdoor temperature and humidity fluctuated significantly, the room temperature and humidity fluctuated reduced, indicating that the room had ample heat storage capacity, and the heavy protective peripheral structure effectively suppressed the temperature and humidity fluctuations.

Table 2. Indoor temperature and humidity (1.5m).

\begin{tabular}{|l|l|c|c|c|c|}
\hline Device name: & & \multicolumn{4}{l|}{ Friday 1/19/2018 22:19:37 } \\
\hline $\begin{array}{l}\text { Start date: 20:00:00 Thursday } \\
\text { 2018/18 }\end{array}$ & & Min & Maximum & Mean & Limits \\
\hline End: $1 / 19 / 2018$ Friday 22:10:00 & no name $\left[{ }^{\circ} \mathrm{C}\right]$ & 6.6 & 19.5 & 10.938 & $-20.0 / 70.0$ \\
\hline Measurement channel: 2 & no name $[\% \mathrm{rH}]$ & 28.9 & 45.3 & 35.812 & $0.0 / 100.0$ \\
\hline Measurements: 158 & & & & & \\
\hline
\end{tabular}




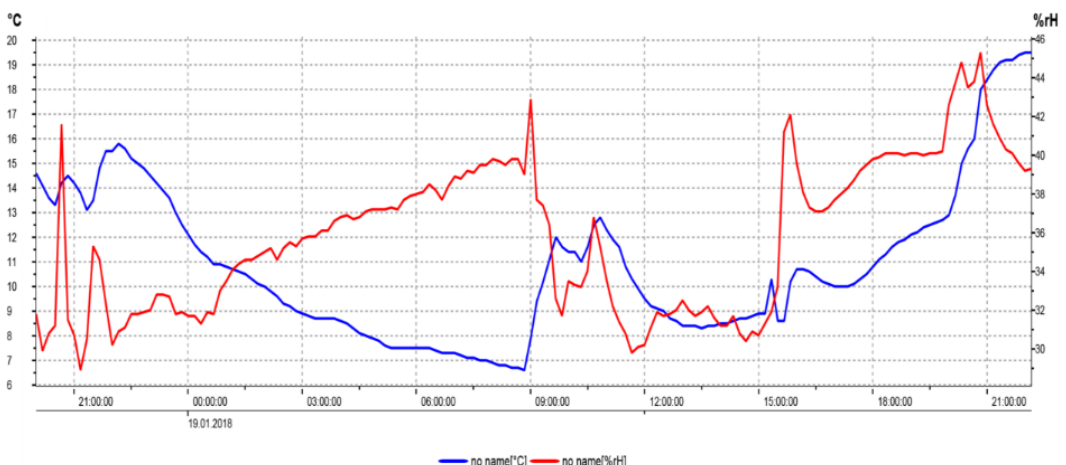

Figure 3. Indoor temperature and humidity line chart (1.5m).

Table 3. Indoor temperature and humidity $(0.6 \mathrm{~m})$.

\begin{tabular}{|c|c|c|c|c|c|}
\hline Device name: & \multicolumn{5}{|c|}{ Friday 1/19/2018 22:09:04 } \\
\hline Start date: 20:00:00 Thursday 2018/18 & & Min & Maximum & Mean & Limits \\
\hline End: 2018/19 Friday 22:00:00 & $\begin{array}{c}\text { no name } \\
{\left[{ }^{\circ} \mathrm{C}\right]}\end{array}$ & 6.1 & 19.6 & 9.766 & $-20.0 / 70.0$ \\
\hline Measurement channel: 2 & $\begin{array}{c}\text { no name } \\
{[\% \mathrm{rH}]}\end{array}$ & 30.6 & 47.9 & 37.405 & $0.0 / 100.0$ \\
\hline Measurements: 157 & & & & & \\
\hline
\end{tabular}

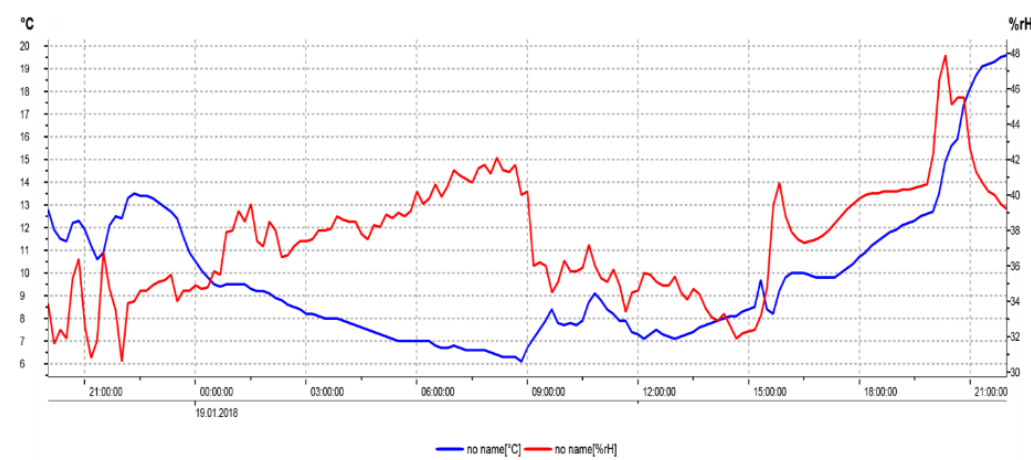

Figure 4. Indoor temperature and humidity line chart (0.6m).

\subsection{Analysis of the temperature monitoring results of the exterior wall surface of the building}

As showed in the figure, on the 19th in the typical building in Dongma village in Xiaojin County, the peripheral wall temperature of the outside wall temperature of manual measurement record, used the Testo830 infrared thermometer and JTNT-A/C multi-channel temperature heat flow tester. Manual measurements were made every half hour from 10:30 to 15:00, with five test points. As can be observed from Figure 5, the outer wall temperature of measuring point 1 (westbound) is from 10:30 to 14:30 gradually increased and reached maximum of $11.2^{\circ} \mathrm{C}$ at $14: 30$. The temperature of the outer wall of the measure 2 (eastbound)is reduced from 10:30 to $1: 30,11: 30$ to $13: 00$ significant increase, $13: 00$ to $14: 30$ there were small fluctuations, $14: 30$ to $15: 00$ significant declined; the outer wall temperature of the measuring point 3 (southbound)showed an overall upward trend from 10:30 to 13:00, but the increase was slight and reached a maximum of $2.8^{\circ} \mathrm{C}$ at 13:00. The outer wall temperature of the measuring point 4 (northbound) was from 10:30 to $11: 30$ showed an overall downward trend, 11:30 to 13:00 presented an overall upward trend and reached the maximum value at 13:00, 13:00 to 15:00 showed an overall downward trend, 11:30 to 13:00 overall showed an upward trend and reached the maximum value at 13:00,14:30 to 15:00 declined substantially. The temperature of the exterior wall of the building was basically the same as that of the outdoor temperature changing, but its temperature value was affected by the orientation, and the north-facing wall had the lowest temperature value in general because it basically did not receive solar radiation. The temperature of the roof began to rise after the sun appeared, and because it was directly exposed to the sun, the temperature value was high when the sun was shining. 
Table 4. Outer wall temperature.

\begin{tabular}{|c|c|c|c|c|c|}
\hline Time & Point 1-West & $\begin{array}{c}\text { Point 2-East } \\
\text { direction }\end{array}$ & $\begin{array}{c}\text { Point } \\
\text { 3-Southdirection }\end{array}$ & $\begin{array}{c}\text { Point 4-North } \\
\text { direction }\end{array}$ & Point 5-Roof \\
\hline $10: 30$ & -1.7 & -6.9 & -3.6 & -6.7 & 1.6 \\
\hline $11: 00$ & -0.4 & -8.8 & -2.4 & -7.7 & 5.8 \\
\hline $11: 30$ & 1 & -11.1 & -1.1 & -10.4 & 5.1 \\
\hline $12: 00$ & 2.2 & -8.8 & 2.3 & -7.9 & 4.8 \\
\hline $12: 30$ & 7.2 & -8.7 & 1 & -9.4 & 9.7 \\
\hline $13: 00$ & 8.4 & -3.3 & 2.8 & -5.6 & 17.7 \\
\hline $13: 30$ & 7.8 & -4.8 & -0.5 & -6.6 & 16 \\
\hline $14: 00$ & 11 & -7.1 & -0.3 & -10.3 & 18.4 \\
\hline $14: 30$ & 11.2 & -8.5 & -8 & -7.4 & 29.2 \\
\hline $15: 00$ & -3.9 & -10 & -4 & -2.5 & 21.3 \\
\hline
\end{tabular}

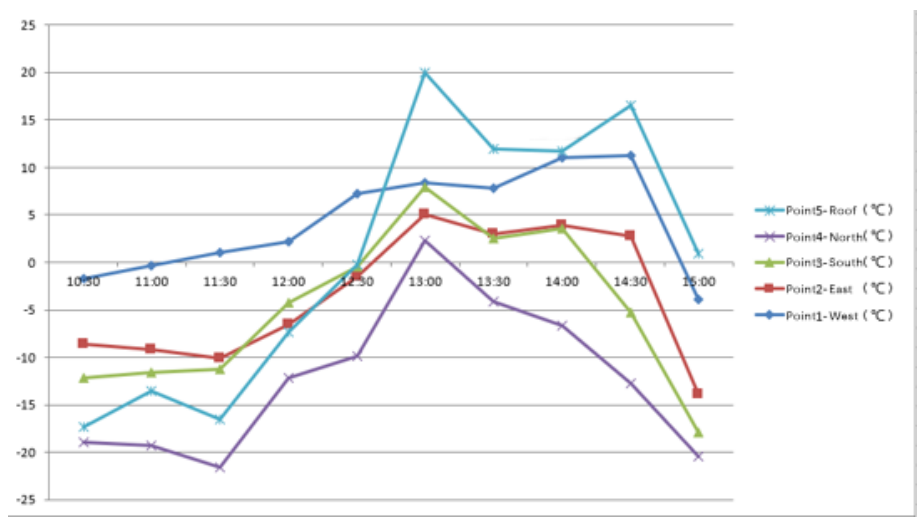

Figure 5. Outer wall temperature line chart.

\section{Optimization recommendations}

\subsection{Room layout}

Additional sunlight room can be set, summer additional sunlight in the afternoon will overheat, the early morning and low temperature, so only as intermittent use of space. However, the inner room of the sunroom can maintain a more comfortable and stable temperature throughout the day, in the summer does not need to set up an auxiliary heat source, this room layout is the Sichuan Plateau residential should be promoted form. In winter, the general humidity in all rooms is low, especially in the living room, the relative humidity is basically maintained at $30 \%$ below the level of humidity measures[2], it is very necessary to take humidity measures, summer room humidity is more suitable, only the average humidity between the sun is low, taking into account the intermittent use of sunlight, in the temperature of the right time can also meet the requirements of humidity comfort, so no additional humidification measures.

\subsection{Walls}

The obvious score of heavy stone walls and exterior walls is the most typical characteristic of traditional local residential, the stones and mud have good thermal performance, and its thermal inert index $\mathrm{D}$ value is large[3], it means the periodic temperature wave decays rapidly in its interior, so it is conducive to winter insulation. However, its insulation capacity is insufficient, it is recommended that we can increase the thickness of the underlying peripheral protective structure, and in the inside of the wall to erase ash, avoid the use of cement such as a large thermal efficiency of building materials, can be used to improve its insulation performance. At the same time, consider the appropriate combination of the Trump Wall and the local traditional residence.

\subsection{Door and window improvements}

Doors and windows are part of the main causes of heat loss in the enclosure structure. Although the customary window insulation performance is good, but the receptive window area is too small, indoor lighting and ventilation conditions are poor[1]. Newly built homes increase the open area of windows, but increase the loss of heat. Therefore, doors and windows need to be opened as far as possible from the wind side, wind side and the north side will open small windows. While paying attention to the size of the vulnerable window position, we also require to pay attention to the ratio of the window to the wall, improve the insulation performance of the doors and windows. Improving the existing properties of door and window materials, such as traditional wood quality although is with good insulation, but as time goes by, the nature and structure of the material will be reduced to varying degrees. Therefore, in the hole seal, can paste paper or use yellow mud to fill 
the gap, if economic conditions is good can also consider the use of polyurethane foaming material for hole sealing, and it can achieve a good wind penetration effect, so as to improve the indoor thermal environment conditions[4].

\subsection{Roof and floor improvements}

As a key part of the enclosure structure, roofing can be considered to set up suitable insulation to reduce heat loss. Due to the large area of the dam, there is a huge gap between the outer wall and the roof, which can lead to a large amount of heat loss[4]. To improve the insulation performance of the roof can start from the enhancement of air tightness at the intersection, such as applying yellow mud at the gap and other ways to reduce heat loss[2].

Human foot and ground direct contact, so the human body will be more sensitive to the ground temperature, stony areas in winter soil temperature are basically lower than the indoor temperature, will cause indoor temperature to the ground loss. Therefore, local insulation treatment can be done along the inner perimeter of the underlying external wall, such as laying such insulation materials as caustic slag in the range of $0.5-1.0 \mathrm{~m}$ on the inside of the outer wall[6].

\subsection{Use of solar energy}

Solar energy has been considered to be a new energy source, it has the advantages of safety, clean and inexhaustible. The amount of solar radiation in northwest Sichuan is very large, so how to improve indoor heating environment and living standards by solar heating and solar lighting has become the current research trend in local residential buildings[2]. However, during the research period found that the local use of solar energy is still in the residents of the small-scale use of the state, such as the use of solar energy hot water, the use of small solar photovoltaic energy storage, etc. Not a large-scale use of its rich solar resources, especially in the use of solar energy to improve the thermal environment of buildings is very few, so how to develop suitable for local building forms and economic level of solar buildings is also a problem to be considered today [5].

\section{Summarize}

This topic has done field testing and research on the current situation of indoor hot and humid environment, and put forward some suggestions for optimizing the indoor hot and humid environment of indigenous customary residential buildings. However, the study of hot and humid environment is only a part of the residential environment, the residential environment system is complex, need to be studied from many aspects in order to improve the living quality of residential, the author in the follow-up study and work process also need to carry out in-depth and detailed research.

\section{References}

1. Shi Xiaona, $\mathrm{Hu}$ Dan, Chen Jian. (2014) Ecological adaptability analysis of Tibetan homes in the Sichuan-West Plateau. J. Sichuan Building Science, 40(04): 314-318.

2. He Quan, Liu Dalong, Zhu Xinrong, Yang Liu, Liu Jiaping. (2015) Sichuan West Plateau Tibetan residential indoor thermal environment test research. J. Xi'an University of Architecture and Technology Journal, 47 (03): 402-406., 2015,47(03): 402-406.

3. Wang Yixuan. (2015) Research on indoor thermal environment in Tibetan traditional residential homes in northwest Sichuan. D. Xi'an University of Architecture and Technology, 45(03): 50-69.

4. Wang Yu, Hou Liqiang. (2018) Study on the optimization of the peripheral protection structure of Tibetan residential in western Sichuan. J. Shanxi Architecture, 44(08): 211-214.

5. Han Cheng, Li Zhongren. (2019) Investigation and analysis of the application of solar energy in residential buildings in Tibetan area. J. Engineering quality, 27(11): 45-48.

6. Wang Wei. (2001) Tibetan Homes in Ganzi State. J. Urban Housing, 35(12): 44-51. 